\section{DE DE GRUYTER} OPEN

G

\author{
Barbara Kożuch*
}

Jagiellonian University, Kraków
Journal of Intercultural Management

Vol. 6, No. 3, September 2014, pp. 5-16 DOI 10.2478/joim-2014-0016

Katarzyna Sienkiewicz-Małyjurek*

Silesian University of Technology, Zabrze

\title{
Organisational consciousness in public safety management system
}

\begin{abstract}
Organisational consciousness is one of the primary determinants driving organisational development. It is the organisation's capacity for assessment of its operation level, quest for uniformity and organisational identity. This consciousness revolves around objectives of actions and integrates collective efforts, thereby determining collaboration. Therefore, it performs a vital role in the public safety management system (PSMS), where efficiency of operations may be achieved only as a result of joint actions. In essence, this was an imperative to carry out research aimed at analysing the significance of organisational consciousness in the public safety management system. During enquiries the authors gave insight into the concepts of organisational consciousness and organisational development as well as characterizing the PSMS in the context of organisational consciousness.

Bearing in mind a comprehensive and adaptive approach to each analysed situation in an individual manner the relevance of organisational consciousness in public safety management systems was found. Furthermore it was testified that organisational consciousness in the PSMS affects three areas, namely: enhances involvement in accomplishment of objectives set, strengthens inter-organisational collaboration and fosters innovative solutions.
\end{abstract}

Key words: organisational consciousness, organisational development (OD), interorganisational collaboration, public safety management system (PSMS), integral theory

\footnotetext{
*barbara.kozuch@uj.edu.pl; katarzyna.sienkiewicz-malyjurek@polsl.pl
} 


\section{Introduction}

The PSMS constitutes a complex structure of units, subgroups and modules, configured differently in each situation depending on needs. Due to the number of entities involved in execution of activities and dynamics as well as complexity of circumstances under which this system operates it represents a research area in the field of OD where Ken Wilber's [Wilber K., 2012; Wilber K., 2006; Wilber K., 2000] integral theory is one of its models. According to this theory, organisational consciousness tends to be an element fuelling OD thanks to dissemination of new ideas to other domains of the development. This enables individual organisations to adjust their operations to standard principles relevant to the system. Keeping in mind that central to fulfilment of tasks within the PSMS is inter-organisational collaboration [Kożuch B. and Sienkiewicz-Małyjurek K'2014b], organisational consciousness plays an important role in actions performed jointly. However, a scope of research carried out in the field of public safety across the world, as evidenced by publications in international scientific literature, appears to be insufficient [Tomasino A.P., 2011], also with regard to factors driving effectiveness of actions. Therefore, the purpose of the paper is to identify the role performed by organisational consciousness in the PSMS as compared to other social factors.

\section{Methodology}

Own studies, providing the foundation for conclusions, were conducted as part of the scientific project entitled" Coordination, communication and confidence as determinants of effective inter-organisational collaboration within the public safety management system", funded by the resources of the National Science Centre based on the decision number DEC-2012/07/D/HS4/00537 over 2013-2014. They involved:

1. Desk research, including:

- analysis of Polish and international body of literature using such databases as: Scopus, ISI Web of Knowledge and Publish or Perish,

- analysis of legislative acts related to actions undertaken by individuals involved in public safety management,

- analysis of internal documents, ordinances and regulations of police, fire brigade and medical rescue in Poland.

- unstructured interviews with 15 junior and mid-level employees employed in police and fire brigade units as well as medical rescue points across Poland

2. Structured interviews conducted with 54 employees in selected emergency communication centres across Poland.

While making analyses the concept of organisational consciousness, OD and PSMS was characterized, thereby identifying the role of organisational consciousness in the PSMS. 


\section{Organisational consciousness versus organisational development}

Organisational consciousness takes place when individual persons align their behaviour and operations to applicable principles. This is a trade-off between individual ambitions and requirements imposed. Overall, this is an effect of experience, interactions at diverse organisational levels, previous learning processes. Organisational consciousness provides foundations for organisational identity which is critical for making decisions and managing changes [Pees R.C., Hostetter Schoop G. and Zieganfuss J.T., 2009]. This is also a requirement for social evolution [Espinosa A. and Harnden R., 2007]. Broadly speaking this suggests possession of general knowledge on the issue addressing the questions: what is the object of actions and why is it [Pruzan P., 2001]?

Organisational consciousness is the key to success of the organisation when pursuing its mission [Pees R.C., Hostetter Schoop G. and Zieganfuss J.T., 2009]. It constitutes a transparent dimension combining organisation elements, thereby providing the basis for a sense of meaning and perception of the organisation as a whole [Dibrell C. et al., 2014]. Essentially, it is exercised through clear and coherent articulation of the role and values of the specific organisation. Phases at which organisation consciousness is developed may be examined at three stages: reflexive, social and collective [Pees R.C., Hostetter Schoop G. and Zieganfuss J.T., 2009, p. 507]. Reflexive phase refers to distinctive attributes of identity, clarifies the sense underlying orgnaization existence based on its unique traits, qualities and achievements. Thus, the focus is brought into itself, its values, targets, quality and competences. At the social phase an organisation explores its relation with surrounding environment and determines its position there. As a result, it becomes less selfcentred, extends its reflexive consciousness, takes into consideration its role, image and responsibility possessed in the larger system to which it belongs. Whereas the collective phase involves mutual relationships fostering increased engagement, understanding and reflection. Due to this function, an organisation becomes a part of the larger and horizontally and vertically integrated system functioning to attain a common goal. Such integration facilitates development of ideas as well as enhanced learning potentials and OD. Accomplishment of the phases of organisational consciousness development is lasting, and each of them is a source for deeper levels of involvement and motivation [Barrett R., 2011, p. 321]. Successful organisations enhance both internal as well as external aspects of consciousness. The focus merely on internal dimensions of consciousness tends to confine innovativeness and ingenuity across organisations. Whilst concentration on external levels of consciousness without cultivation of internal levels constrains capabilities for effective operations as well as generates ineffectiveness, impracticality and no references to reality of operations. Basically, these features sometimes surface in operations performed by non-governmental organisations [Barrett R., 2011, p. 322]. Threfore, a full spec- 
trum of organisational consciousness manifests itself by positive attributes of its internal as well as external dimesnion. Both dimensions constitute a backbone of orgnaiztaional development which appears to be a broad, long-term approach aimed to enhance the functioning level for the organisation while boosting efficiency of its operations. The concept applies to changes in human resources, essence and quality of labour relationshops, though it often covers the issues concerned with structural and technological changes. Operations with regard to OD results form the following premises [Kożuch B., 2011, p. 216]

- people have a natural desire for personal excellence and development;

- employees are characterized by a strong need to be accepted by other organisation memebers;

Whereas the strategy in OD relies on the following premises [Webber R.A., 1996, p. 515-520; Kożuch B., 2011, p. 217]:

- systematic improvement of what was good in past ragther than revolutionary changes are the most desired;

- groups (teams) form a fundamental structure of the organisation;

- important aim of the change is bolstered collaboration among specific organisation elemenst;

- in an appropriately organised orgnaiztion decisions are made where information sources are based rgather than at some predetermined levels;

- an organisation as a whole and its indivisual elements always pursue a predetermined objective;

- one of the objectives in the organisation is to establish an information system, mutual trust among specific elements;

- people support what they create.

The concept of OD argues that at the heart of sustainable performance of the organisation are values and employees' behaviours [Foster C., 2013]. Involved employees have to believe in what they do and see the meaning of their actions. There are numerous approaches to implemenetation of OD. For example in order to bring about organisational efficiency the following steps are used [Mullins L.J., 2007, p. 720-721]:

1. Survey research and feedback with questionnaire surveys determining the attitudes of members to the organisation functioning.

2. Senility training groups concentrating on increasing participants' sensitivity to the emotional reactions, their diagnostic ability, and their behavioural flexibility and effectiveness.

3. Team building as a process of diagnosing task procedures and patterns within a work group.

4. Grid training aimed at attaining an orientation to maximum concern for both production and people. 
Another OD approach, which requires sophisticated social and behavioural process skills, offers six steps described as follows [Shukla M., 2011, p. 207-208]:

1. Entry of an external change agent.

2. Preliminary diagnosis the relevant problem issues by the change agent.

3. Feedback to the client system - the findings of the diagnosis presentation.

4. Discussion and decision on an action plan.

5. Action implementation.

6. Further data collecting and diagnosis.

No matter what approach is used for preparation and implementation of OD, organisational consciousness is necessary as alongside OD there is growing complexity of processes [Cacioppe R. and Edwards M.G., 2005b, p. 233]. At each progress level the move to a higher level occurs in the consciousness domain in the first place. Thus, consciousness goes beyond the lower levels of the structures and it is able to integrate and harness them for further development. Consciousness of integration of initiatives launched by varied institutions contributes to increased coherence of operations among organisations and augmented innovativeness of enterprises [Cacioppe R. and Edwards M.G., 2005b, p. 231]. The role of organisational consciousness in OD was illustrated in Figure 1.

Figure 1: The role of organisational consciousness in OD

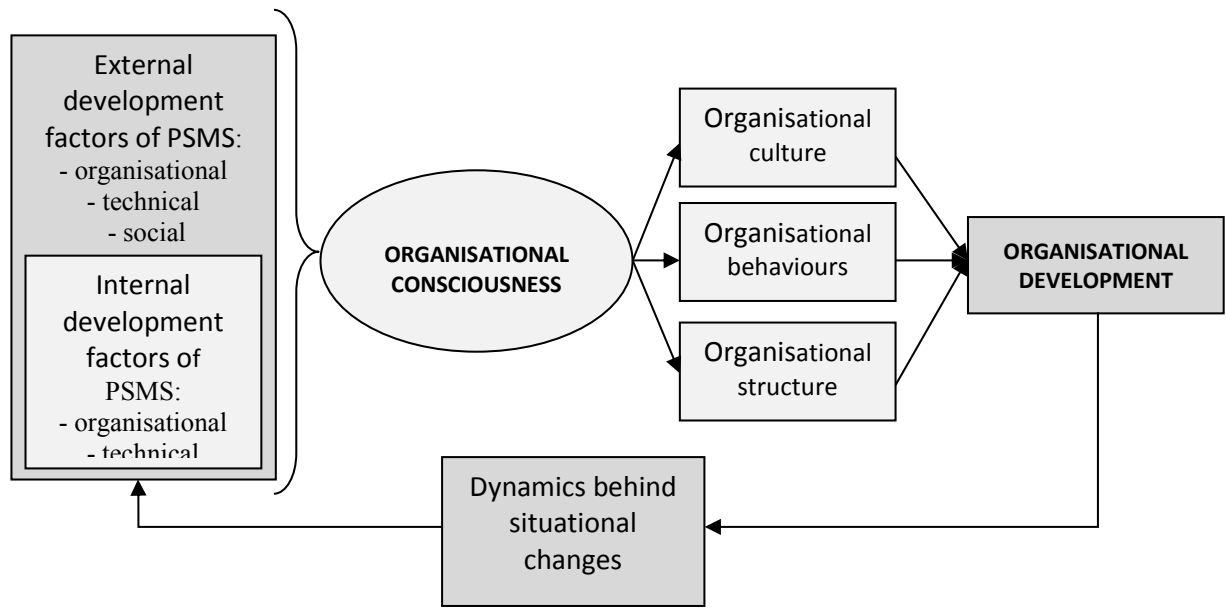

Source: study based on: [Wilber K., 2012; Wilber K, 2006; Pruzan P., 2001; Pees R.C., Hostetter Schoop G. and Zieganfuss J.T., 2009; Cacioppe R. and Edwards M., 2005a; Cacioppe R. and Edwards M., 2005b]

Understanding the role played by consciousness in an organisation enables to determine in which it may be used in decision-making processes, and further it provides opportunities for increasing the number of changes and boosting their efficiency. The primary objective in organisational consciousness analysis is to deploy 
theoretical knowledge for strengthening performance of the organisation [Pees R.C., Hostetter Schoop G. and Zieganfuss J.T., 2009, p. 505]. Given the specifics underlying public safety management it may be claimed that attributes of organisational consciousness carry great importance in this respect.

\section{Public safety management system}

Public safety as a category of public management is regarded as the mainstay of wealthy and well-functioning society since it is an effect of state policy pursued [Kożuch B., 2004, p. 60; Choenni S. and Leertouwer E., 2010, p. 234]. It refers to geo-phisical conditions, current and potential threats as well as regional infrastructure. Public safety incorporate an entirety of initiatives launched by public administration in the form of regulatory policy as well as planning and orgnizational operations in order to provide society with adequate safety level and swift assistance when specific threat occurs. A traditional approach to public safety revolves around delivery of target through formulation of appropriate public policies. Currently, the need for a new approach which puts an emphasis on management issues acquired urgency [Kożuch B. and Sienkiewicz-Małyjurek K., 2014a, p. 473].

On the whole, it is assumed that enterprises run in public safety management are based on collaboration, and units involved execute parallel operations which mutually complement [Waugh W.L. and Streib G., 2006; Berlin J.M. and Carlström E.D., 2011; Kapucu N., Arslan T. and Demiroz F., 2010]. These units form the PSMS intended to fulfil one of the primary social need - need for safety. In Poland this assumptions stems from applicable laws and tasks assigned to these units which suggest the urgency for their collaboration. These entities include [Kożuch B. and Sienkiewicz-Małyjurek K., 2014b]:

1. Local government;

2. Response and rescue units, including:

- a core unit whose competences involve taking actions in response to an emerging specific type of threat;

- basic units which mostly respond collectively and collaborate in public safety management;

- ancillary units being complimentary to actions taken by a core unit and basic units, whose knowledge and competences are essential in the specific situation;

3. Society: local communities and enterprises;

4. Media: radio, TV, press, Internet;

5. Non-governmental organisations;

6. Research and development units, e.g. laboratories, higher education institutions, research institutes.

A basic level at which the PSMS operates is local government - district (town/ city having the district rights) together with communes [Kulesza M., 2008, p. 354]. 
At this level a civil leadership in the field of safety reside in the staroste (president of the city/town having the district rights), and consequently all services, inspections and guards whose operations are concerned with maintaining public safety are subject to its civil authority. Local governments are charged with initiating ventures to tackle local threats, securing financial funds for their execution as well as monitoring the progress of these operations and controlling their effects. Local government fulfils its tasks independently, and government administration has an opportunity of supervising and coordinating its operations within applicable laws [Act of 23 January 2009 on voivodeship and government administration; Act of 5 June 1998 on voivodeship self-government; Act of 8 March 1990 on commune self-government; Act of 26 April 2007 on crisis management]. Leading executive entities include units specializing in handling specific threats, and their scope of activities results from statutory tasks. For social threats occurred a leading unit of Police, for natural threats - State Fire Brigade, for epidemics - Chief Sanitary Inspectorate, for epizooty - Veterinary Inspectorate, etc. These entities accomplish their tasks under circumstances of risk and uncertainty. Furthermore, the PSMS is characterised by complexity, volatility and varying intensification of operations, depending on needs and situations. Therefore, this system may be only comprehended from the comprehensive perspective, incorporating both external and internal drivers as well as formal and informal relations. Equally, the integral theory may be helpful as it makes it possible to take into consideration systemic structures and uncertainty in OD.

\section{The development factors of public safety management system}

In public safety management OD may emerge in the continuous as well as cyclical mode. Continuous changes apply to any planned initiatives taken to strengthen effectiveness of operations (e.g. joint training). Whereas cyclical changes trigger bigger changes in culture and organisational behaviours. They may stem from, among others, experience gained while executing actions. The key role in this respect is played by the dynamics behind changes in situational circumstances as well as conditions for development of the organisation and their employees. Entities participating in operational activities constitute complementary units whose role changes depending on the situation, type of event and hazard. In this regard legal and organisational requirements create the basis for initiating actions. Though, without identifying social requirements they fail to be factors sufficient to ensure efficacy of operations performed in this area, because not all relations may be included in operational procedures [Kożuch B., Sienkiewicz-Małyjurek K. and Kożuch A.J., 2014]. While investigating three major factor groups having an impact on actions taken in the PSMS were classified. They are as follows [Kożuch B. and SienkiewiczMałyjurek K., 2014b]: 
- organisational factors,

- technical factors,

- social factors.

Organisational factors pertain to existing collaboration principles and requirements likely to foster collaboration between organisations or to hinder it. They cover applicable legal regulations and the aspects developed by the organisations themselves on the basis previous experience. Technical factors refer to devices, equipment and technologies used enabling accomplishment of collaboration processes in public safety management. Whilst social factors embrace organisational factors, both formal and informal relations between organisations, as well as the level of relations between organisations. The last group also includes organisational consciousness concerned with knowledge about competencies of individual organisations, the need for collaboration as well as possible options for executing operations. Principally, it allows for integration of principles prevailing in specific units across the PSMS to ensure efficacy of jointly performed actions.

\section{The significance of organisational consciousness in public safety manage- ment system - the results of research}

One of the research elements was the evaluation of the importance of effectiveness factors influencing actions in the PSMS. Assessing the significance of organizational consciousness on the background of other social factors it was found that analyseed factor is on the same level as goodwill in relations with other organisations, but lower than specialisation in activities, commitment in operations and trust between organisations. These results are illustrated in Figure 2.

Figure 2: Assessing the significance of organizational consciousness on the background of other social factors

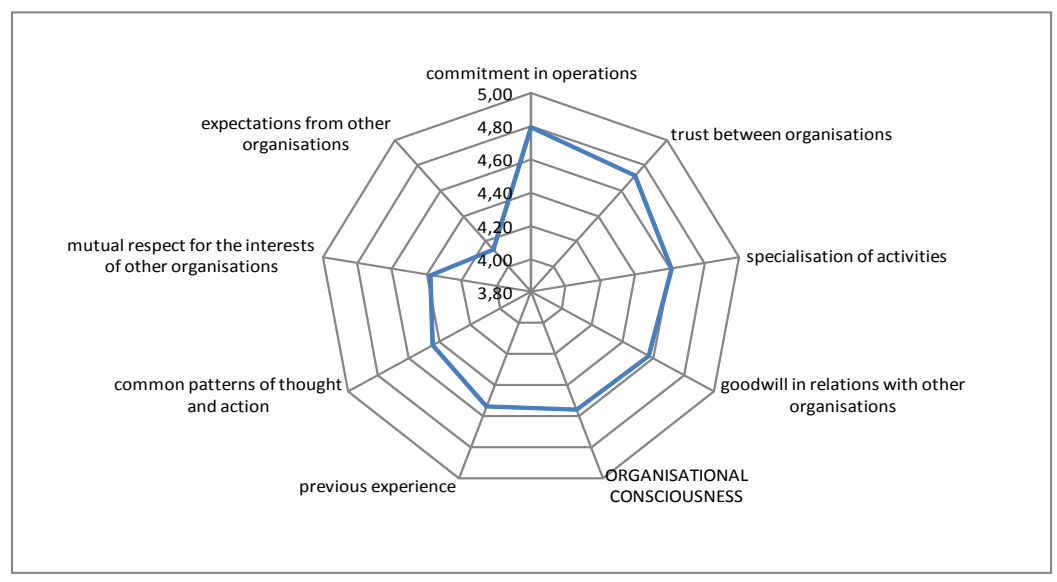

Source: own elaboration based on the study completed. 
Based on the studies completed it was also stated that lack of organisational consciousness may lead to:

- problems in conducting response and rescue actions,

- failure to reach consensus between organisations involved in actions,

- ineffectiveness of actions,

- destabilization of the PSMS,

- threat to life and health of officers, rescuers and other persons engaged in operations, and consequently loss of trust between organisations.

The respondents also attributed great significance to experience, conceptual approach to the given issue, and the role of continued advancement of operations which provides the bedrock for organisational consciousness. Organisational consciousness in units across the PSMS transcends the bounds of one single organisation. After all, those surveyed are aware that they form part of the larger organism and contemplate their role performed in actions jointly accomplished. Furthermore, these units strive for further betterment, which is the effect of recognizing the importance of integrated operations.

Consequently, it may be stated that the meaning of organisational consciousness in executing operations in a bid to guarantee public safety has not been fully examined. However, in-depth interpretations of the research findings suggest that in many cases its role in the PSMS is intuitively experienced.

The relevance of organisational consciousness in public safety management stems from the need for a comprehensive and adaptive approach to each situation in an individual manner. Each event proceeds at another place, with varying scale and intensity, and it is beset by other perils likely to trigger escalation of threats. Hence, actions undertaken in the PSMS progress differently, and additionally similar resources are engaged in actions, though with varying strength and configuration. For this reason, units within the PSMS are required to realise their role in operations conducted. All in all, having analysed the findings from interviews it was concluded that organisational consciousness in the PSMS affects in three areas, namely: enhances involvement in accomplishment of objectives set, strengthens inter-organisational collaboration and fosters innovative solutions.

Situational circumstances have implications for factors driving development of units within the PSMS, thereby affecting factors behind development of the whole system. Whilst development factors determine the shape and pace of evolution of organisational consciousness, which then exerts an influence in involvement into targets embraced, inter-organisational collaboration and innovative measures. As a consequence, it ultimately shapes organisational culture, behaviours and structure which, from the comprehensive perspective, provide directions for OD within the PSMS. This development alters along the dynamics behind situational shifts. 


\section{Conclusions}

This study provides an overview of the significance of organisational consciousness in the PSMS. Even though the research concept was properly developed and organizational consciousness was characterised, the nature of this investigation was essentially exploratory. The key cause for this situation lies in the limitation of fieldwork which covered only police, fire brigade and medical rescue units. In future the surveys will be expanded and incorporate more entities of the PSMS.

1. Despite these limitations, this study addresses the relevance of organisational consciousness which in management studies is novelty and need to be tighter examined. As the result of research conducted to investigate the role of organisational consciousness within the PSMS, it was concluded that:The role of organisational consciousness within the PSMS stems from situational circumstances which have an impact on factors guiding development of the system units.

2. Organisational consciousness within the PSMS affects three spheres: enhances involvement in accomplishment of target embraced, strengthens inter-organisational collaboration and fosters innovative solutions.

3. A distinctive trait of organisational consciousness within the PSMS is that it transcends the bounds of individual units which form the system.

4. Relevance of organisational consciousness in practice of operations to ensure public safety has not been sufficiently recognized, and further research in this field is strongly recommended.

\section{References}

Act of 8 March 1990 on commune self-government (Journal of Laws of 2001 No. 142, item 1591 , as amended).

Act of 23 January 2009 on voivodeship and government administration (Journal of Laws 2009 No. 31 item 206).

Act of 26 April 2007 on crisis management (Journal of Laws of 2007 No. 89, item 590, as amended).

Act of 5 June 1998 on voivodeship self-government (Journal of Laws of 2001 No. 142, item 1590 , as amended.).

Barrett, R. (2011), The New Leadership Paradigm, The Values Center.

Berlin, J.M. and Carlström, E.D. (2011), Why is collaboration minimised at the accident scene?: A critical study of a bidden phenomenon, Disaster Prevention and Management, vol. 20, iss: 2, pp.159-171.

Cacioppe, R. and Edwards, M.G. (2005a), Adjusting blurred visions: A typology of integral approaches to organisations, Journal of Organizational Change Management, vol. 18, iss: 3, pp. 230-246.

Cacioppe, R. and Edwards, M.G. (2005b), Seeking the Holy Grail of organisational devel- 
opment: A synthesis of integral theory, spiral dynamics, corporate transformation and action inquiry, Leadership \& Organization Development Journal, vol. 26, iss: 2, pp.86-105.

Choenni, S. and Leertouwer, E. (2010), Public Safety Mashups to Support Policy Makers, First International Conference, EGOVIS 2010, Bilbao, Spain, August 31 - September 2, Springer-Verlag Berlin Heidelberg, p. 234-248.

Dibrell, C., Craig, J.B., Kim, J. and Johnson A.J. (2014), Establishing How Natural Environmental Competency, Organizational Social Consciousness, and Innovativeness Relate, Journal of Business Ethics, January 30, p. 1-15.

Espinosa, A. and Harnden, R. (2007), Complexity Management, Democracy and Social Consciousness: Challenges for an Evolutionary Learning Society, Systemic Practice and Action Research, vol. 20, pp. 401-412.

Foster, C. (2013), Re-conceptualizing the role of organizations in society: challenging the status quo using organizational development, Development and Learning in Organizations, vol. 27, iss: 6, pp.7-9.

Kapucu, N., Arslan, T. and Demiroz, F. (2010), Collaborative emergency management and national emergency management network, Disaster Prevention and Management, vol. 19, iss. 4, pp. $452-468$.

Kożuch, B. (2011), Nauka o organizacji, Warszawa: CeDeWu Sp. z o.o.

Kożuch, B. (2004), Zarzqdzanie publiczne w teorii ipraktyce polskich organizacji, Warszawa: Placet.

Kożuch, B., Sienkiewicz-Małyjurek, K. and Kożuch, A.J. (2014), Effective Organisational Communication in Local Emergency Networks, Wulfenia, vol. 21, no. 7, pp. 193-219.

Kożuch, B. and Sienkiewicz-Małyjurek, K. (2014a), New Requirements for Managers of Public Safety Systems, Procedia - Social and Behavioral Sciences, vol. 149, pp. 472-478.

Kożuch, B. and Sienkiewicz-Małyjurek, K. (2014b), Collaborative Performance In Public Safety Management Process, International Scientific Conference Lumen 2014 - 5th editin: Transdisciplinarity and Communicative Action, in press.

Kulesza, M. (2008), Budowanie samorzqdu, Warszawa: Municipium.

Mullins, L.J. (2007), Management and organisational behaviour, Essex: Prentice Hall.

Pees, R.C., Hostetter Schoop, G. and Zieganfuss, J.T. (2009), Organizational consciousness, Journal of Health Organization and Management, vol. 23, no. 5, pp. 505-521.

Pruzan, P. (2001), The Question of Organizational Consciousness: Can Organizations Have Values, Virtues and Visions?, Journal of Business Ethics, vol. 29, pp. 271-284.

Shukla, M. (2011), Understanding Organisations, New Delhi: PHI Learning Private Limited.

Tomasino, A.P. (2011), Public Safety Networks as a Type of Complex Adaptive System, Proceedings of the Eighth International Conference on Complex Systems, New England Complex Systems Institute Series on Complexity NECSI Knowledge Press, pp. 1350-1364.

Waugh, W.L. and Streib, G. (2006), Collaboration and Leadership for Effective Emergency Management, Public Administration Review, vol. 66, pp. 131-140.

Webber, R.A. (1996), Zasady zarzadzania organizacjami, Warszawa: PWE. 
Wilber, K. (2012), In defense of integral theory: a response to critical realism, Journal of Integral Theory and Practice, vol. 7, no. 4, pp. 43-52.

Wilber, K. (2006), Integralna teoria wszystkiego: wizja dla biznesu, polityki, nauki i duchowości, Poznań: Wydawnictwo „Zysk i S-ka”.

Wilber, K. (2000), Psychologia integralna: świadomość, duch, psychologia, terapia, Warszawa: Wydawnictwo Jacek Santorski \& Co. 